\title{
Penerapan Algoritma Apriori Dengan Market Basket Analysis Untuk Pengaturan Tata Letak Barang
}

\author{
Putri Andriani ${ }^{1}$, ,Lelah.lelah ${ }^{2}$ \\ ${ }^{1), 2)}$ Prodi Teknik Informatika, Universitas Muhammadyah Sukabumi \\ Correspondent Author : pandriani9912@gmail.com \\ DOI: https://doi.org/10.37012/jtik.v7i2.633
}

\begin{abstract}
Abstrak
Penelitian ini bertujuan untuk membantu pihak toko untuk menganalisa barang apa saja yang sering dibeli dalam kurun waktu tertentu dan diletakkan saling berdekatan dan agar memperoleh proses penataan tata letak barang pada display area dengan mempertimbangkan pola pembelanjaan pelanggan untuk memudahkan dalam menemukan produk yang akan di beli secara bersamaan dengan menggunakan algoritma apriori. Data data yang yang terlibat dalam setiap transaksi penjualan pada sares Gallery sehingga terjadinya tumpukan data yang dibiarkan saja.untuk itu digunakanlah metode market basket analysis untuk menyelesaikan masalah yang dihadapi. Kemudian, sistem akan menjalankan proses penghitungan nilai dukungandari setiap kumpulan data transaksi yang ada dalam rentang waktu tersebut dan memilih sesuai dengan nilai dukungan minimum. Dalam menetapkan aturan asosiasi yang hendak ditunjuk, maka tentu harus mengurutkan terlebih dahulu berdasarkan support $x$ confidence. Aturan tersebut akan diambil sebanyak $\mathrm{n}$ aturan yang mempunyai hasil terbesar. Maka, diambil kesimpulan tiga item yang sering dibeli bersamaan adalah Baju, sandal, dompet.
\end{abstract}

Kata Kunci : algoritma apriori, market basket analysis, tata letak barang

\begin{abstract}
This study aims to help the store to analyze what items are often purchased within a certain time and are placed close to each other and to obtain the process of arranging the layout of goods in the display area by considering customer spending patterns to make it easier to find products to be purchased simultaneously. using the a priori algorithm. The data involved in each sales transaction is in the Sares Gallery so that a pile of data is left alone. For this reason, the market basket analysis method is used to solve the problems encountered. Then, the system will run the process of calculating the support value from each transaction data set that exists in that time range and selecting according to the minimum support value. In determining the association rules to be appointed, you must first sort them based on support x confidence. The rule will be taken as many as $n$ rules that have the largest result. So, it can be concluded that the three items that are often bought together are clothes, sandals, and wallets.
\end{abstract}

Keywords: a priori algorithm, market basket analysis, goods layout 


\section{PENDAHULUAN}

Kemajuan yang begitu cepat dalam bidang teknologi informasi tentunya berdampak sangat luar biasa ke dalam aspek kehidupan manusia. Hal tersebut dapat dirasakan dalam perubahan-perubahan aspek kehidupan yang terjadi secara mendasar salah satunya seperti bagaimana seseorang dapat melakukan komputasi, yang biasa dilakukan dalam kegiatan pemasaran. Sares Gallery adalah salah satu jenis usaha yang menjual busana dan aksesoris seperti tas, pakaian, sandal, gantungan kuci dan aksesoris lainnya. Sares Gallery ini merupakan suatu elemen yang sangat penting, sehingga sebagai manajemen yang baik dalam proses mengatur tata letak dan ketersediaan stok barang sangat diperlukan, untuk menghindari penumpukan barang yang sama dan barang yang kurang diminati oleh pembeli.

Berbagai strategi dapat digunakan untuk tata letak barang di toko, antara lain kedaan toko tersebut secara aktual, kemungkinan yang akan terjadi jika membaca dari tren terbaru, dan gambaran umum mengenai proses belanja seorang konsumen berdasarkan transaksi penjualan. Dengan menggunakan data yang sudah ada, pada penelitian ini, peneliti menggunakan data transaksi penjualan dari sampel toko Busana dan aksesoris bernama Sares Gallery dan menganalisanya dengan menggunakan algoritsma Apriori.

Dalam proses transaksi jual beli atau market basket dalam proses analisis nya biasanya menggunakan algoritma apriori, algoritma apriori juga digunakan untuk memahami pola ataupun gambaran umum mengenai proses pembelian suatu barang oleh konsumen sehingga misalnya ada barang $\mathrm{X}, \mathrm{Y}$, dan Z, dan konsumen tersebut telah membeli barang $\mathrm{X}$ dan $\mathrm{Y}$, maka kemungkinan konsumen akan membeli juga barang $\mathrm{Z}$ adalah 50\%, gambaran seperti ini harusnya bisa diolah oleh suatu sistem yang sudah memiliki daftar transaksi jual beli sehingga dapat menentukan barang mana yang harusnya berdekatan disimpan di rak ataupun mendukung keputusan tata letak barang lainnya.

Bersumber pada hasil kajian terdahulu mengenai algoritma apriori. Penulis menelaah beberapa penelitian, ada beberapa yan memiliki keterkaitan dengan peneliian yang penuls lakukan .

Penelitian yang dilakukan oleh [1] metode yang digunakan ialah data mining dan algoritma yang tepat untuk menganalisis data. Adapun sistem yang dibangun mememakai Visula Basic 6.0 untuk melengkapi penentuan mode pembelian obat. Sistem ini digunakan untuk mengetahui ada tidaknya obat dan tempat penyimpanan obat dari mode pembelian obat, sehingga dapat lebih mudah mencari item obat. diatur dari 2 itemset obat.

Penelitian yang dilakukan oleh [2] menyimpulkan bahwa penelitian tersebut dapat mengetahui hasil hubungan yang terjadi dalam keterikatan barang antara satu dengan yang lainnya. Dari hasil itu pula, dapat digunakan dalam mengatur tempat penyimpanan barang.

Penelitian yang dilakukan oleh [3] penerapan algoritma Apriori dan FP-Growth dalam melakukan penelitian analisis keranjang pasar pada setiap item penjualan produk buku telah menghasilkan banyak aturan asosiasi yang berbeda antara satu algoritma dengan algoritma lainnya.

Penelitian yang dilakukan oleh [4] ialah membangun suatu sistem yang dapat menghasilkan waktu penambahan data dari setiap algoritma yang digunakan. Dari hasil 
penambahan waktu tersebut bisa digunakan dalam melakukan analisis kecepatan dari setiap algoritma dalam menambah data.

Penelitian yang dilakukan oleh[5] dapat disimpulkan bahwa dalam membentuk aturan asosiasi dari database yang digunakan dalam melakukan transaksi penjualan yaitu dengan menggunakan algoritma apriori dengan memanfaatkan pemprograman java sehingga hasilnya dapat diperoleh aturan asosiasi pemasaran lainnya.

\section{METODE PELAKSANAAN}

Metode penelitian yang di gunakan yaitu metode penelitian gabungan atau mixed method, karena penelitian ini menggabungkan tahapanpengumpulan data, analisis data, dan gabungan secara sekuensial,yaitu kuantitatif dan kualitatif untuk digunakan menyimpulkan penelitian. .

Dalam penelitian ini penulis mengimplementasikan algoritma apriosi dengan Market Basket Analysis, Ada beberapa pembahasan mendasar yang menjelaskan tahapan dalam merancang sistem dengan mengimplementasikan algoritma apriori. Adapun tahapan penelitian yang akan dilakukan adalah sebagai berikut:

1. Pengumpulan data

Pada tahap ini Penulis menggunakan tiga metode untuk mengumpulkan data pada penelitian kali ini yaitu observasi dilakukan dengan cara mendatangi Sares Galery dan mengamati keadaan toko dan proses pengaturan tata letak barang yang dilakukan di sares gallery, wawancara dilakukan terhadap karyawan toko yang bertugas melakukan proses pengaturan tata letak barang di sares gallery

2. Tahapan dalam implementasi algoritma

a) Analisis Pola Frekuensi Tinggi dengan Algoritma Apriori

Dalam tahapan ini akan dicari kombinasi item yang memenuhi syarat minimum dari nilai support dalam database.

b) Analisis Pembentukan Kombinasi 2 Itemset Sementara

Dalam tahapan ini, frequent itemset akan memperlihatkan itemset yang mempunyai frekuensi kemunculan lebih dari nilai minimum yang telah ditentukan (Ø). Contohnya jika $\emptyset=2$, maka semua itemsets yang frekuensi kemunculannya lebih dari atau sama dengan 2 kali disebut frequent set.

c) Analisis Pembentukan Aturan Asosiasi

Dalam memilih aturan asosiasi, maka terlebih dahulu harus mengurutkan berdasarkan support x confidence. Dalam penerapannya, aturan akan diambil sebanyak $\mathrm{n}$ aturan yang mempunyai hasil paling besar. 


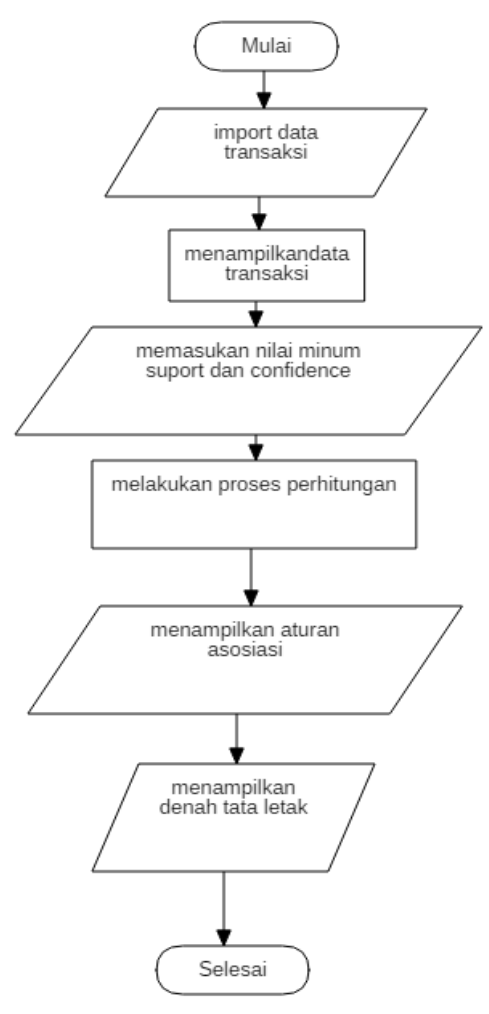

Gambar.1 Flowchart Algoritma apriori

\section{Perhitungan Manual Algoritma apriori}

1. Gunakan algoritma Apriori untuk analisis pola frekuensi tinggi., gunakan rumus berikut:

Support A $=\sum$ Transaksi Mengandung A x 100\%

\section{¿Transaksi}

2. Tahap pembentukan kombinasi 2 item sementara, gunakan rumus untuk mendapatkan nilai support 2 item sebagai berikut: $\operatorname{Support}(\mathrm{A}, \mathrm{B})=\mathrm{P}(\mathrm{A} \cap \mathrm{B})$

Support A,B $=\sum$ Transaksi Mengandung A dan B x 100\%...(2)

\section{$\sum$ Transaksi}

3. Pembentukan Aturan Asosiasi Setelah menemukan semua pola frekuensi tinggi, kemudian hitung aturan keyakinan asosiasi A-> B untuk menemukan aturan asosiasi yang memenuhi persyaratan minimum. Nilai confidence dari aturan A-> B diperoleh dengan rumus sebagai berikut:

Confidence $=\sum$ Transaksi Mengandung A dan B x 100\%

\section{$\sum$ Transaksi A}

Untuk menentukan aturan asosiasi yang akan dipilih, mereka harus diurutkan berdasarkan Support $\times$ Confidence. Mengadopsi aturan $N$ dengan hasil paling banyak.[7] 


\section{Alur Algoritma}

Adapun tata Cara kerja algoritma apriori yaitu :

1. Menentukan nilai minimum support.

2. Iterasi 1 , dimana pada tahapan ini dilakukan perhitungan pada setiap item support dengan mengambil dari database untuk 1 itemset, jika diperoleh hasil sesuai kriteria minimum support, maka 1 itemset tersebut akan menjadi pola frequent tinggi.

3. iterasi w, dimana pada tahapan ini dilakukan kombinasi dari $\mathrm{k}$ itemset sebelumnya agar mendapatkan 2 itemset dengan alur seperti pada iterasi 1.

4. Selanjutnya, menetapkan nilai $\mathrm{k}$ itemset support yang sesuai kriteria minimum support dari k itemset.

5. Terakhir, untuk iterasi selanjutnya, gunakan alur tahapan diatas secara berulang sehingga tidak ada lagi k itemset yang sesuai kriteria minimum support.

\section{HASIL DAN PEMBAHASAN}

Pada bagian ini penulis memaparkan mengenai hasil yang diperoleh dari penelitian yang dilakukan, berupa Model Prototype produk dan beberapa tampilan interface utama aplikasi dan hasil pengujian.

\section{Pengumpulan Data}

Data hasil dari observasi dan wawancara kepada pegawai toko yang dilakukan oleh penulis sehingga menghasilkan data yang dapat digunakan oleh penulis untuk melihat keadaan dan tata letak barang secara langsung, adapun daftar data yang telah berhasil penulis kumpulkan adalah data transaksi yang memiliki kode pada setiap transaksi yang terjadi pada toko tersebut.

Tabel 1 data Barang

\begin{tabular}{clc}
\hline No & Nama barang & Stok \\
\hline 1 & Baju & 200 \\
\hline 2 & Tas & 75 \\
\hline 3 & Sandal & 200 \\
\hline 4 & Kalung & 50 \\
\hline 5 & Gantungan Kunci & 150 \\
\hline
\end{tabular}


Tabel 2 data Transaksi

\begin{tabular}{lll}
\hline No & ID & Item \\
\hline 1 & 001. & tas,baju,dompet,sandal \\
\hline 2 & 002. & baju,sandal,kalung \\
\hline 3 & 003. & tas,sandal,gantungan \\
\hline 4 & 004. & baju,tas,kalung,dompet \\
\hline 5 & 005. & sandal,kalung,tas \\
\hline 6 & 006. & gantungan,kalung,baju \\
\hline 7 & 007. & tas,baju,sandal,dompet \\
\hline 8 & 008. & kalung,baju,tas \\
\hline 9 & 009. & sandal,tas,kalung \\
\hline 10 & 010. & baju,sandal,tas,dompet \\
\hline
\end{tabular}

\section{Pehitungan manual algoritma}

Dalam perhitungan manual kali ini, penulis akan melakukan dengan menggunakan data yang telah diambil dari sares gallery sawarna Lebak Banten. Analisis Pola Frekuensi Tinggi dengan Algoritma Apriori, dalam tahapan ini akan dicari kombinasi item yang memenuhi syarat minimum dari nilai support dalam database. Tabel 1 merupakan sample transaksi pada sares gallery:

Tabel 3 tabel transaksi barang yang dibeli

\begin{tabular}{cl}
\hline Id & \multicolumn{1}{c}{ Barang yang dibeli } \\
\hline 001. & \{tas,baju,dompet,sandal\} \\
\hline 002. & \{baju,sandal,kalung\} \\
\hline 003. & \{tas,sandal,gantungan\} \\
\hline 004. & \{baju,tas,sandal,dompet \\
\hline 005. & \{sandal,kalung,tas $\}$ \\
\hline 006. & \{gantungan,kalung,baju\} \\
\hline 007. & \{tas,baju,sandal,dompet \\
\hline 008. & \{kalung,baju,tas \\
\hline 009. & \{sandal,tas,kalung \\
\hline 010. & \{baju,sandal,tas,dompet \\
\hline
\end{tabular}

Untuk penyederhanaan nama-nama item di table 1 dipersingkat, dan hanya huruf pertama yang digunakan sebagai contoh.:

$\mathrm{T}=$ Tas $\quad \mathrm{K}=$ Kalung

$\mathrm{B}=$ Baju $\quad \mathrm{GK}=$ Gantungan Kunci

$\mathrm{S}=$ Sandal $\quad \mathrm{D}=$ Dompet

Sehingga menjadi seperti tabel 2 berikut ini 
Tabel 4 Tansaksi barang yang dibeli

\begin{tabular}{ll}
\hline ID Transaksi & \multicolumn{1}{c}{ Item } \\
\hline 001. & $\{\mathrm{~T}, \mathrm{~B}, \mathrm{D}, \mathrm{S}\}$ \\
\hline 002. & $\{\mathrm{~B}, \mathrm{~S}, \mathrm{~K}\}$ \\
\hline 003. & $\{\mathrm{~T}, \mathrm{~S}, \mathrm{GK}\}$ \\
\hline 004. & $\{\mathrm{~B}, \mathrm{~T}, \mathrm{~S}, \mathrm{D}\}$ \\
\hline 005. & $\{\mathrm{~S}, \mathrm{~K}, \mathrm{~T}\}$ \\
\hline 006. & $\{\mathrm{GK}, \mathrm{K}, \mathrm{B}\}$ \\
\hline 007. & $\{\mathrm{~T}, \mathrm{~B}, \mathrm{~S}, \mathrm{D}\}$ \\
\hline 008. & $\{\mathrm{~K}, \mathrm{~B}, \mathrm{~T}\}$ \\
\hline 009. & $\{\mathrm{~S}, \mathrm{~T}, \mathrm{~K}\}$ \\
\hline 010. & $\{\mathrm{~B}, \mathrm{~S}, \mathrm{~T}, \mathrm{D}\}$ \\
\hline
\end{tabular}

Tahapan ke 1 : hitung berapa banyak transaksi untuk setiap item

Tabel 5 banyaknya transaksi per item

\begin{tabular}{cc}
\hline Item & $\begin{array}{c}\text { Banyaknya } \\
\text { Transaksi }\end{array}$ \\
\hline $\mathrm{B}$ & 7 \\
\hline $\mathrm{T}$ & 8 \\
\hline $\mathrm{S}$ & 7 \\
\hline $\mathrm{K}$ & 4 \\
\hline $\mathrm{GK}$ & 2 \\
\hline $\mathrm{D}$ & 4 \\
\hline
\end{tabular}

Langkah ke 2 : Sesuai golden rule filter data pada Tabel 3 hanya pilih item yang memiliki transaksi minimal sebanyak 7 transaksi, dan buang item yang kurang dari 7 transaksi.Hasilnya ditunjukkan pada Tabel 4.

Tabel 6 item yang paling sering di beli

\begin{tabular}{cc}
\hline Item & $\begin{array}{c}\text { Banyaknya } \\
\text { Transaksi }\end{array}$ \\
\hline $\mathrm{B}$ & 7 \\
\hline $\mathrm{T}$ & 8 \\
\hline $\mathrm{S}$ & 7 \\
\hline
\end{tabular}

Frequent item set akan memperlihatkan itemset yang mempunyai frekuensi kemunculan lebih dari nilai minimum yang telah ditentukan $(\varnothing)$. Contohnya jika $\varnothing=2$, maka semua itemsets yang frekuensi kemunculannya lebih dari atau sama dengan 2 kali disebut frequent set. Seperti Langkah berikut : buat pasangan item di mulai dari item pertama yaitu TB, TS kemudian di lanjutkan dengan item kedua TS 


\section{Table 7 Pasangan Item

\begin{tabular}{c}
\hline Pasangan Item \\
\hline $\mathrm{TB}$ \\
\hline $\mathrm{TS}$ \\
\hline $\mathrm{TD}$ \\
\hline $\mathrm{BS}$ \\
\hline $\mathrm{BD}$ \\
\hline $\mathrm{DS}$
\end{tabular}

langkah ke 4 : hitung berapa kali suatu pasangan item dibeli bersamaan

\section{Tabel 8 item yang paling sering di beli}

\begin{tabular}{cc}
\hline $\begin{array}{c}\text { Pasangan } \\
\text { Item }\end{array}$ & $\begin{array}{c}\text { Banyaknya } \\
\text { Transaksi }\end{array}$ \\
\hline TB & 2 \\
\hline TS & 5 \\
\hline TD & 4 \\
\hline BS & 4 \\
\hline BD & 4 \\
\hline DS & 3 \\
\hline
\end{tabular}

Langkah 5 : gunakan golden rule, hapus semua pasangan item yang banyaknya transaksi kurang dari 3.

Table 9 transaksi pasangan item paling banyak

\begin{tabular}{cc}
\hline $\begin{array}{c}\text { Pasangan } \\
\text { Item }\end{array}$ & $\begin{array}{c}\text { Banyaknya } \\
\text { Transaksi }\end{array}$ \\
\hline TS & 5 \\
\hline TD & 4 \\
\hline BS & 4 \\
\hline BD & 4 \\
\hline
\end{tabular}

Langkah ke 6: buat pasangan 3 item dengan aturan menggunakan item pada table 7 yng memilii huruf pertama yang sama yaitu

1. $\mathrm{TS}$ dan $\mathrm{TD}=\mathrm{TSD}$

2. $\mathrm{BS}$ dan $\mathrm{BD}=\mathrm{BSD}$

Lalu hitung berapa banyak transaksi dari pasangan 3 item berdasarkan table 2 dapat dilihat hasilnya pada table 4.8

Table 10 banyak transaksi 3 pasang item

\begin{tabular}{cc}
\hline $\begin{array}{c}\text { Pasangan } \\
\text { Item }\end{array}$ & $\begin{array}{c}\text { Banyaknya } \\
\text { Transaksi }\end{array}$ \\
\hline TSD & 3 \\
\hline BSD & 4 \\
\hline
\end{tabular}

Langkah ke 7 gunakan lagi golden rule dengan menghapus 3 pasangan iem yang transaksinya kurang dari 4, hasilnya tinggal BSD karena TSD Hanya dibeli bersamaaaan 3 kali 
Kesimpulan : tiga item yang serng dibeli bersamaan adalah B,S,D

Untuk menentukan aturan asosiasi yang akan dipilih maka harus diurutkan berdasarkan Support $\times$ Confidence. Aturan diambil sebanyak $n$ aturan yang memiliki hasil terbesar. Untuk menemukan tingkat kepercayaan, kumpulan item yang sering (yaitu $\{B, S, D\}$ ) dapat digunakan untuk menemukan aturan asosiasi antara item dalam Frequent Itemset tersebut,dengan cara:
a. $\{B\}$
b. $\{S\}$
c. $\{\mathrm{D}\}$
d. $\{\mathrm{B}, \mathrm{S}\}$
e. $\{S, D\}$
f. $\{B, D\}$

Cari asosiasi pada semua himpunan bagan yang telah dibuat seperti di bawah ini:

$\{B\} \Rightarrow\{S, D\}$ artinya : jika B di beli bagaimana kemungkinan $S$ dan $D$ akan di beli pada transaksi yang sama, B dibeli pada 4 transaksi dan di dalam 4 transaksi tersebut S dan D Juga dibeli maka keyakinannya adalah : 4/4 x 100\% =100\%

$\{\mathrm{S}\}=>\{\mathrm{B}, \mathrm{D}\}$ : Confidence adalah $4 / 5 \times 100 \%=60 \%$

$\{D\}=>\{B, S\}:$ Confidence adalah $4 / 3 \times 100 \%=75 \%$

$\{\mathrm{S}, \mathrm{D}\}=>\{\mathrm{B}\}:$ Confidence adalah $4 / 4 \times 100 \%=100 \%$

$\{\mathrm{B}, \mathrm{D}\}=>\{\mathrm{S}\}$ : Confidence adalah $4 / 4 \times 100 \%=100 \%$

$\{\mathrm{B}, \mathrm{K}\}=>\{\mathrm{D}\}$ : Confidence adalah $4 / 3 \times 100 \%=100 \%$

\section{SIMPULAN}

\section{Kesimpulan}

Bersumber pada penelitian yang telah dilakukan, terdapat beberapa kesimpulan yang dapat ditarik diantaranya sebagai berikut:

1. Penerapan algoritma Apriori dengan market Basket Analysis pada pengaturan tata letak barang di sares gallery berjalan dengan lancar

2. Pada penelitian ini diketahui dari 6 jenis barang, barang yang sering dibeli bersamaan adalah baju sandal dan dompet.

\section{Saran}

Berdasrkan kesimpulan diatas, maka saran yang diharapkan yaitu dilakukan pengembangan pada Sares Gallery Banten adalah sebagai berikut:

1. Pembuatan Pengaturan tata letak pada ares Gallery Banten ini masih banyak kerurangan dan masih bias dikembangkan sesuai kebutuhan.

2. Selain itu juga diharapkan dapat meningkatkan penjualan pada Sares Galerry Banten. 


\section{REFERENSI}

G. Gunadi and D. I. Sensuse, "Penerapan Metode Data Mining Market Basket Analysis Terhadap Data Penjualan Produk Buku Dengan Menggunakan Algoritma Apriori Dan Frequent Pattern Growth ( Fp-Growth ) :," Telematika, vol. 4, no. 1, pp. 118-132, 2012.

H. N. Wulandari and N. W. Rahayu, "Pemanfaatan Algoritma Apriori untuk Perancangan Ulang Tata Letak Barang di Toko Busana," Semin. Nas. Apl. Teknol. Inf. ( SNATI ), vol. 6, no., p. D-33D-38, 2014.

M. Marsono, "Penerapan Data Mining Pengaturan Pola Tata Letak Barang Pada Berkah Swalayan Untuk Strategi Penjualan Menggunakan Algoritma Apriori," InfoTekJar (Jurnal Nas. Inform. dan Teknol. Jaringan), vol. 3, no. 2, pp. 170-175, 2019, doi: 10.30743/infotekjar.v3i2.908

R. Yanto and R. Khoiriah, "Implementasi Data Mining dengan Metode Algoritma Apriori dalam Menentukan Pola Pembelian Obat," Creat. Inf. Technol. J., vol. 2, no. 2, p. 102, 2015, doi: $10.24076 /$ citec. $2015 \mathrm{v} 2 \mathrm{i} 2.41$.

S. Suprayogi and A. Karima, "Implementasi Algoritma Apriori dengan Market Basket Analysis untuk Pengaturan Tata Letak Produk," Sisfotenika, vol. 9, no. 2, p. 169, 2019, doi: 10.30700/jst.v9i2.477..

V. Nomor et al., "Analisis Perbandingan Algoritma Apriori Dan Algoritma Hash Based Pada Market Basket Analysis Di Apotek Uad," JSTIE (Jurnal Sarj. Tek. Inform., vol. 3, no. 1, pp. 1-10, 2015, doi: 10.12928/jstie.v3i1.2896.

V. N. Budiyasari, P. Studi, T. Informatika, F. Teknik, U. Nusantara, and P. Kediri, "Implementasi Data Mining Pada Penjualan kacamata Dengan Menggunakan Algoritma Apriori," Indones. J. Comput. Inf. Technol., vol. 2, no. 2, pp. 31-39, 2017. 